\title{
Research and Evaluation in Medical Education
}

\author{
Dr Helena A. Ferris ${ }^{1} \&$ Dr Mary E. Collins ${ }^{2}$ \\ ${ }^{1}$ Lecturer in Clinical Medicine, Trinity College Dublin, Ireland \\ ${ }^{2}$ Senior Executive Development Specialist, Institute of Leadership, Royal College of Surgeons Ireland \\ Correspondence: Dr Helena A. Ferris, Lecturer in Clinical Medicine, Trinity College Dublin, Ireland. E-mail: \\ ferrish@tcd.ie
}

Received: June 19, 2015

Accepted: July 13, 2015

Online Published: July 22, 2015

doi:10.5430/ijhe.v4n3p104

URL: http://dx.doi.org/10.5430/ijhe.v4n3p104

\begin{abstract}
The landscape of medical education is continuously evolving, as are the needs of the learner. The appropriate use of research and evaluation is key when assessing the need for change and instituting one's innovative endeavours. This paper demonstrates how research seeks to generate new knowledge, whereas evaluation uses information acquired from research to make decisions as to how well a particular practice is working and whether or not changes or improvements are required (Polit D \& Beck C. 2007).

Ideally evaluation and research should be synergistic as both research and evaluation seek evidence for developing practice (Fain J., 2005). However, in reality this is challenging as there can often be a dichotomy between the two. Increasingly, medical educators and researchers are working as part of multidisciplinary teams so that a collective picture can be generated using 'evaluative research'. Not only is this a more efficient way of analysing information, but it also encourages the sharing of knowledge across professional borders (Mitchell $\mathrm{R}$ et al. 2015).

It is evident that research and evaluation are of the utmost importance and will continue to be a cornerstone of both modern day evidence based medicine and medical education.
\end{abstract}

Keywords: Research, Evaluation, Medical Education

\section{Introduction}

The landscape of medical education is continuously evolving, as are the needs of the learner. During the past decade, medical education has undergone significant reform to cater for the needs of the modern day students of "Generation Y' (Strauss \& Howe, 2000), who are information rich but time poor (Taylor \& Sheehan, 2011). In general, there has been a shift from the traditional teacher centred approach to more student centred learning, which is characterised by active participation and autonomous learning (Hedge et al, 2011). This was born from the demand for a dynamic curriculum that is receptive to global trends and more dependent on technology so that students can take charge of their own development (Larson et al, 2009).

However, one must ask how medical educators became aware of the needs and evolving expectations of students? Furthermore, how did they assess the merits and limitations of implementing such changes? This paper discusses how an appropriate use of research and evaluation is key when assessing the need for change and instituting one's innovative endeavours.

In this article, we will firstly explore the world of research in medical education and its origins. Secondly, we will analyse the relationship between research and evaluation. Finally, we will briefly examine some of the models of evaluation available today.

\section{Research}

When we delve into the world of research, we see that its use in the arena of medical education is relatively new. The first fully funded sustained research into improving teaching and learning in medical schools was in the 1950's, nearly half a century after the famous Flexner report (Kuper et al, 2010), (Hitchcock, 2002), (Flexner, 1910). Despite the late start, this area has flourished and its progression is reflected in the innumerable medical education and research journals available today.

One can only postulate as to what prompted this explosive growth in medical education research but it's felt that a number of socio-historic factors converged and led to an appreciation of the fundamental obligation for the 
advancement of knowledge within the medical community (Deitrick \& Berson, 1953). Many of these factors are still drivers of research today such as; the exponential growth in medical knowledge, increasing importance of scientific research, concerns about accountability for and control of medical education (Albert, 2004), (Albert et al, 2007).

In modern day medicine, research is of the highest priority, not only within academic medicine but in everyday clinical practice. The Irish Medical Council (IMC) now stipulate that at least one research audit must carried out annually in order to remain on the IMC register (Irish Medical Council, 2015). The importance of research has been further emphasised in recent national reports such as the Hunt report, which emphasised the importance of research as one of the core competencies of a modern day doctor (Hunt et al, 2011). After all, without research and knowledge advancement, we cannot possibly hope to remain at the forefront of best international practice nor can we attract enterprise or investment. With this in mind, many universities such as Trinity College Dublin (TCD) now offer an intercalated Master's program to $3^{\text {rd }}$ year medical students in order to foster a culture of research at an early stage in their career (Webster \& Kenny, 2011). This ethos continues in the postgraduate phase where many governing bodies such as the Royal College of Physicians Ireland (RCPI) and the Royal College of Surgeons in Ireland (RCSI) are committed to formally integrating medical research into postgraduate training programs (Royal College of Physicians Ireland, 2015).

Research can take on many forms but ultimately it involves the systematic investigation into sources in order to establish facts and reach new conclusions (Oxford Dictionary, 2015). Research has become one of the cornerstones of modern day medical practice as we need to be able to make informed decisions based on best evidence rather than on anecdotal evidence so that we can offer our patients the optimal treatment course. Broadly speaking, quantitative and qualitative research methods are used to address research problems (Figure No. 1). Although both of these methods are inherently different in their approach i.e. quantitative research is based on a quantifiable measurement process, whereas qualitative research is descriptive and subjective, they can both contribute to the evidence base in a complimentary manner (Tavakol \& Sandars, 2014). Traditionally, clinical medicine had held quantitative research in higher esteem as it is based on statistical figures and so is more tangible than qualitative research. However, in recent years, we have seen a growing appreciation of qualitative research, which is used more often in the arena of medical education (Tavakol et al, 2008). It is clear that there is no 'one size fits all' approach to research methods as each approach to inquiry is appropriate in a different research setting and often a mixed methods approach is utilised in a bid to maximise new insights into a particular area.

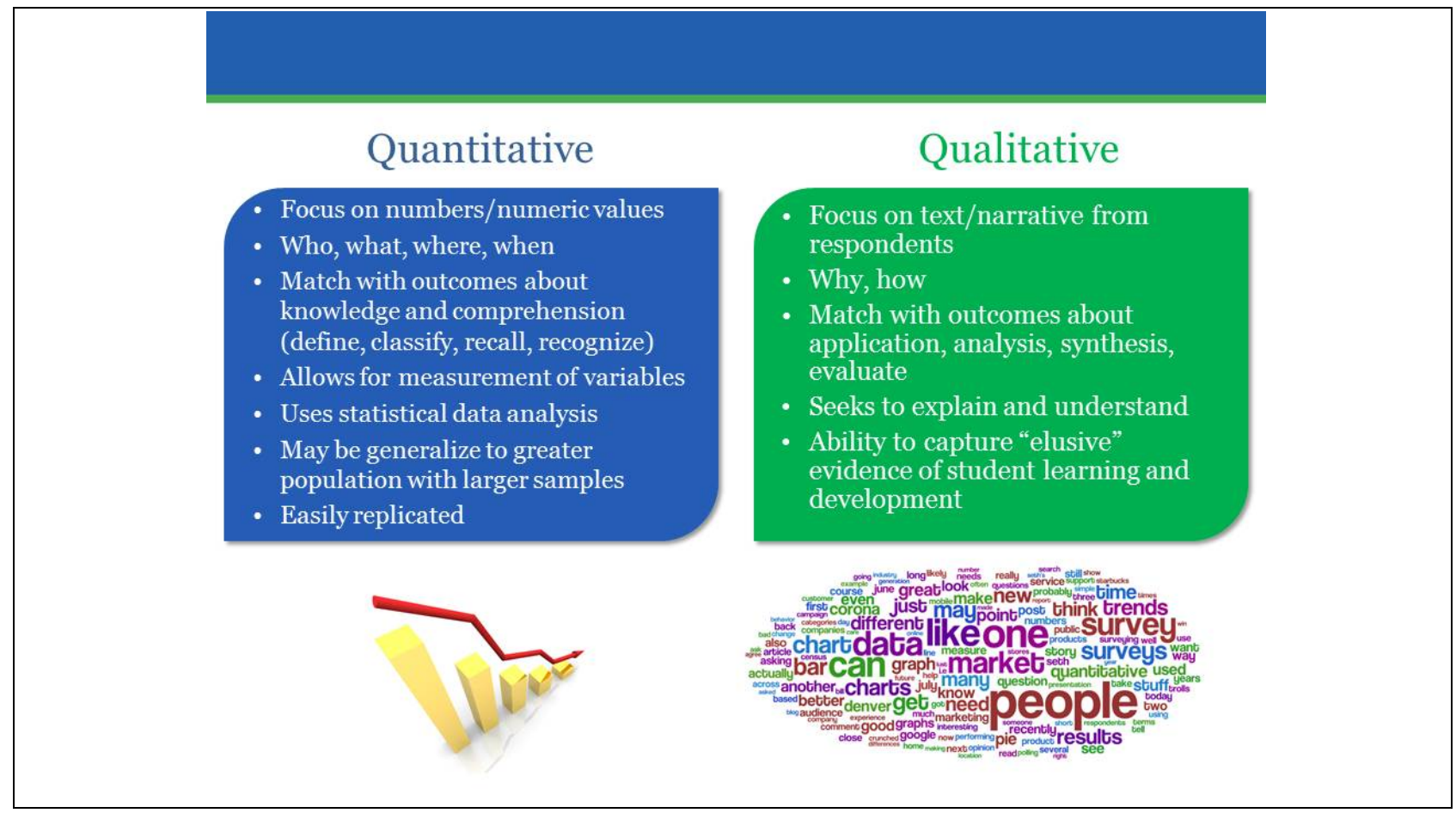

Figure 1. Quantitative versus Qualitative Approaches

Adapted from Quantitative vs. Qualitative Measures, available at

http://baselinesupport.campuslabs.com/hc/en-us/article_attachments/201672385/Quantitative_vs_Qualitative.jpg 


\section{Relationship between Research and Evaluation}

Evaluation is a form of applied research that scrutinises how well a particular practice, program or policy is working (Tavakol et al, 2010). Whereas research generally seeks to generate new knowledge, evaluation uses information acquired from research to make decisions as to how well a particular practice is operating and whether or not changes or improvements are required (Figure No. 2) (Polit \& Beck, 2010).

Ideally evaluation and research should be synergistic as both research and evaluation seek evidence for developing practice (Fain, 2005). However, in reality this can be challenging as there can often be a dichotomy between research and evaluation. For example, evaluators tend to focus on context, localised results and the interests of the stakeholders, whereas researchers focus more on generating or building on existing knowledge, replication of results and methodological rigour (Morrison, 2003), (Holzemer W, 1980). However, we are increasingly seeing medical educators and researchers working as part of multidisciplinary teams so that a collective picture of a particular practice or topic can be generated using 'evaluative research' (Polit \& Beck, 2010). This is particularly pertinent in planning medical education programs and many postgraduate training bodies have now formed taskforces in a bid to improve postgraduate training in Ireland so that we can try to retain Irish graduates within the Irish medical system (Ferris \& Joyce, 2015). These teams usually comprise of medical educators, consultants and trainees from the particular training scheme in question and government representatives who are responsible for funding. Not only is this a more efficient way of analysing information and enhancing a particular program or practice, but it also encourages the sharing of knowledge across professional borders (Mitchell et al, 2015).

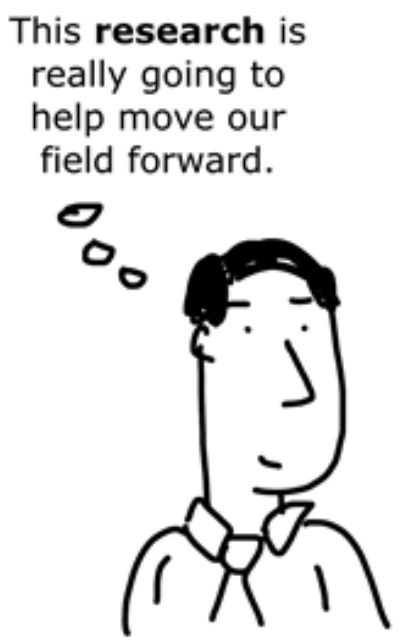

\section{This evaluation is really going to help our program become more effective.}

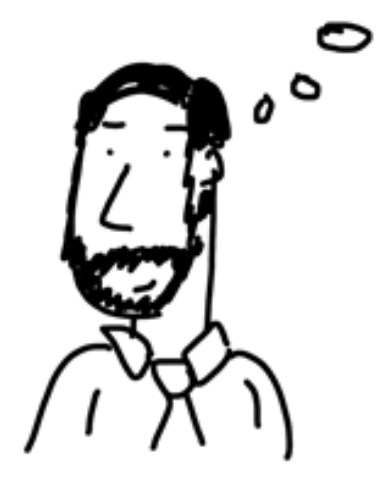

Figure 2. Pictorial Representation of the Relationship Between Research and Evaluation

Adapted from Michael Quinn Patton's Evaluation 5 Cartoons. (2014) Available at http://freshspectrum.com/wp-content/uploads/2014/07/wpid-Photo-201407150621494.jpg

\section{Evaluation Models}

As we have discussed so far, evaluation is a key component of medical education and medical research as it fosters a culture of both accountability and improvement. Over the last decade there has been a growing appreciation of the role of evaluation in both public and private decision making processes. This has been reflected in national strategic planning documents, which have included evaluation as a key element in not only change management, but in meeting the needs and expectations of service users (Figure No.3). 


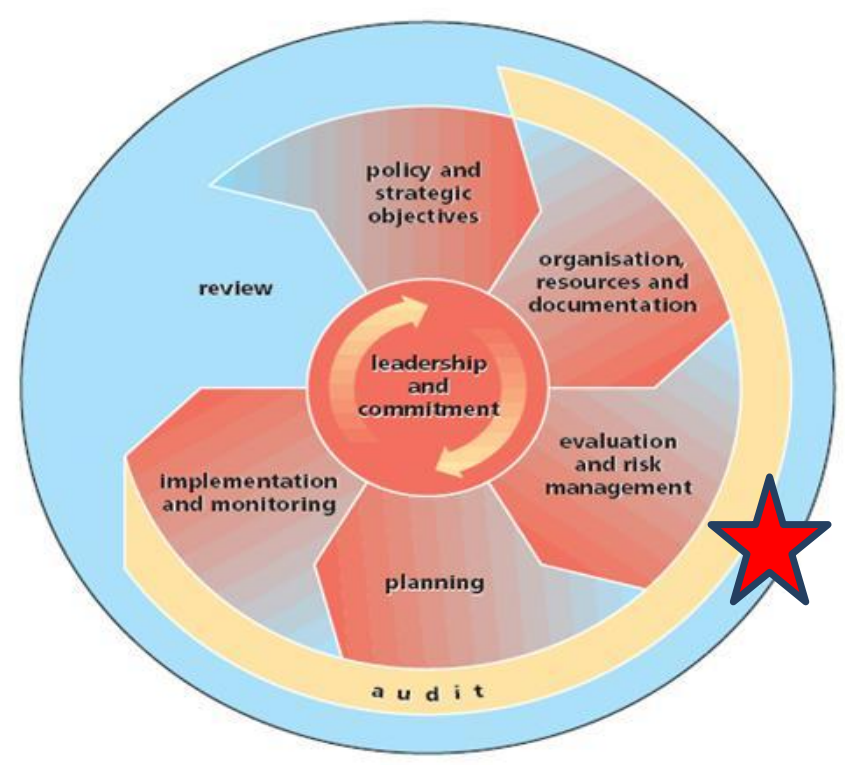

Figure 3. Health Service Executive Change Model

Adapted from the Irish Health Service Executive Policy (2008). A user's guide to managing change in the Health Service Executive, Dublin. Available at http://hse.ie/eng/staff/Resources/hrstrategiesreports/Improving_our_Services,_A_Guide_to_Managing_Change_in_t he_the_HSE_-_Oct_2008.pdf

Evaluation in education is well established and dates back to the influential Ralph Tyler almost a century ago (Joyce, 2010), (Tyler, 1930). Today, there are countless evaluation models available, with each model having inherent pros and cons. These models have evolved from various theories underpinning evaluation, namely reductionism, systems theory and complexity theory (Yardley \& Dornan, 2012). Some of the more well-known approaches to evaluation include naturalistic evaluation, fourth generation evaluation, Kirkpatrick's model, Jacobs' model, CIPP model, logic model and more recently, empowerment and self-evaluation models (McNamara et al, 2010). The addition of more modern approaches such a self-evaluation is particularly interesting as it utilises one's own critical thinking skills, which in turn encourages both personal and professional development. In practice, a combination of methods is often used in order to enhance the quest for improvement and professional development.

Let us look briefly at some of the more commonly used evaluations models in medical education. The Kirkpatrick evaluation model was introduced over four decades ago and has been used extensively for evaluating educational programs (Yardly \& Dornan, 2012). Originally, it consisted of four levels (reaction, learning, impact and results) with a fifth level being added later by Philips to measure return on investment (Figure No. 4) (Philips, 2003). It is an outcome based model and its main advantage is that it provides a clear framework for analysing educational programs. However, one has to be cognisant of the fact that it does not take into account factors that can affect learning outcomes such as motivation, knowledge base etc (McNamara, 2010). It has also been criticised for assuming that there is a linear relationship between educational programs and outcomes, which isn't always the case (Sufflebeam \& Shinkfield, 2007). 


\section{Kirkpatrick's Model of Training Evaluation}

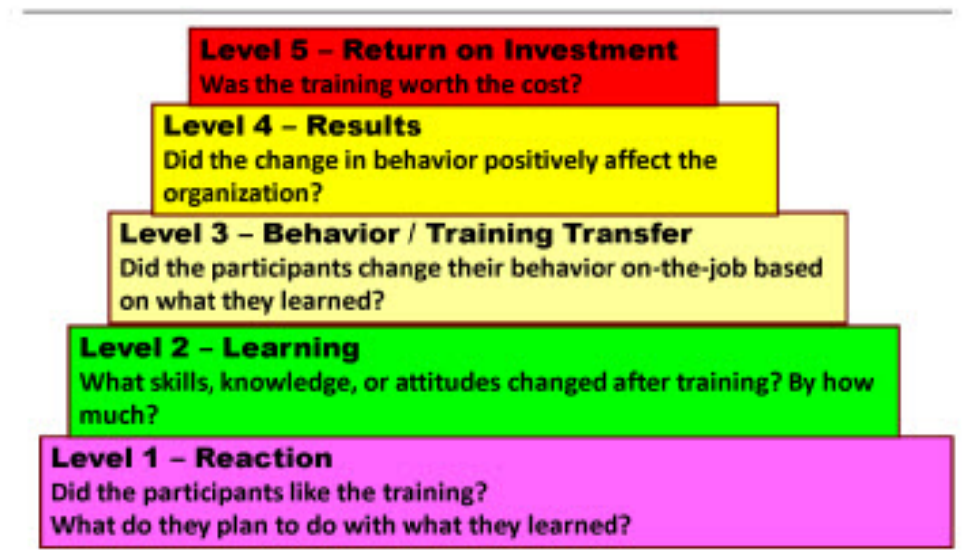

Figure 4. Kirkpatricks Evaluation Model

Adapted from Salas E. (2009) Patient safety training evaluations; reflections on level 4 and more. Available at http://archive.ahrq.gov/news/events/conference/2009/salas/index.html

The Logic model is a linear evaluation model that can also be used for planning and evaluating educational programs (Weiss, 1972). Its uncomplicated design makes it an attractive choice (Figure No. 5). It consists of four basic components (Inputs, activities, outputs and outcomes) but it can be expanded by adding feedback loops or adding tiers if a more complex analysis is required (Frechtling et al, 2007), (Patton, 2011).

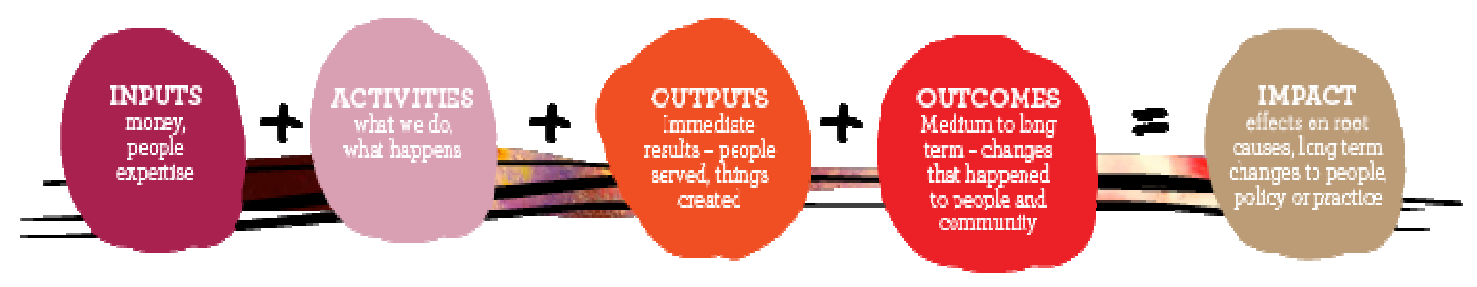

Figure 5. Logic Model

Adapted from the Impact Value Chain basic logic model developed by Weiss, C.H. (1972). Available at http://4.bp.blogspot.com/-JUxl2CcG2mk/VRnv08XfZRI/AAAAAAAAAIs/w3zN6CQ9Hkg/s1600/BE_diagram1.pn $\mathrm{g}$

The CIPP (context/ input/ process/product) model is useful as it can be adapted to both educational and non-educational settings (Figure No. 6) (Stufflebeam, 1983). It is a process based thorough model of evaluation that can be applied at any stage of a program development i.e. when planning a new program, assessing a mature program or evaluating a program after its completion. Its main advantage is that it is non-liner and so provides a dynamic framework for looking at many different aspects of an educational program (Figure No. 6). However, it requires careful planning and is labour intensive as multiple data collection methods are often required in order to carry out an efficient CIPP evaluation. 


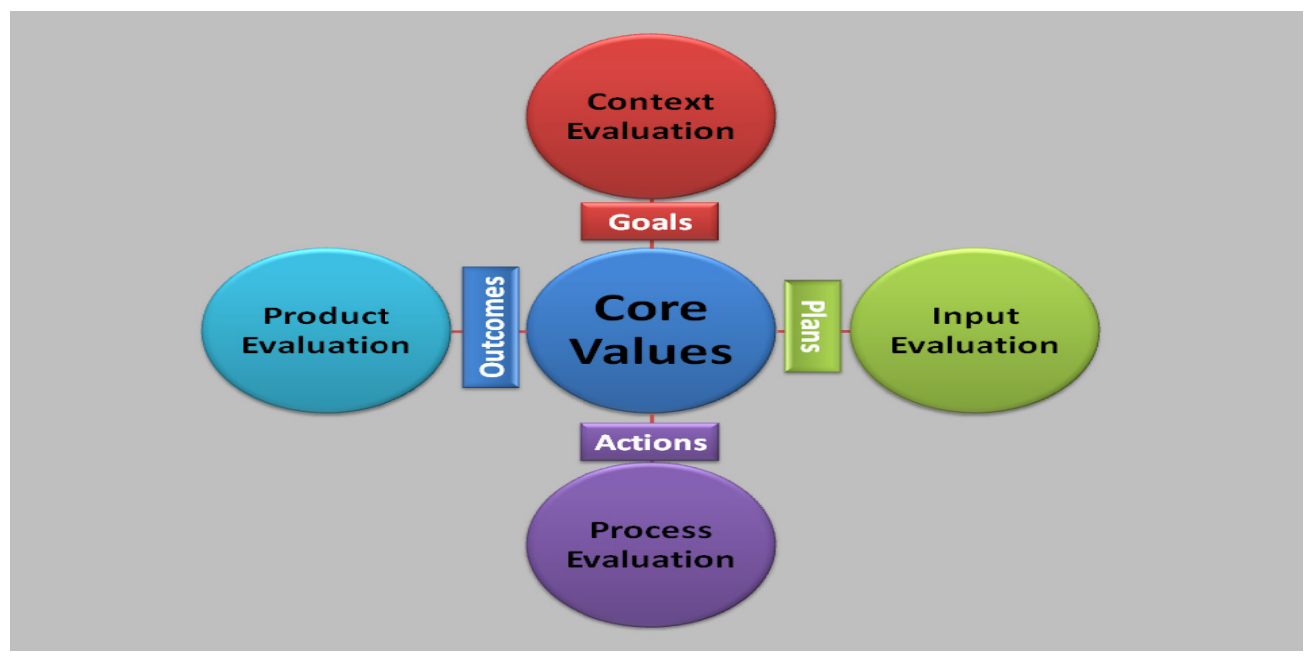

Figure 6. CIPP Model

Adapted from Stufflebeam's CIPP Model 1983. Available at http://arcmit01.uncw.edu/jonesi/Images/CIPPEvaluationModel.png

As with most methods of evaluation, there is no one 'perfect' evaluation model, however, it is important to choose a model that will help you the collect information needed to determine the merit or worth of your educational program (Cook, 2010).

\section{Conclusion}

The landscape of medical education is continuously evolving, as are the needs of the learner. The appropriate use of research and evaluation is key when assessing the need for change and instituting one's innovative endeavours. This paper illustrates how research generally seeks to generate new knowledge, whereas evaluation uses information acquired from research to make decisions as to how well a particular practice is operating and whether or not changes or improvements are required (Polit \& Beck, 2007).

Ideally evaluation and research should be synergistic as both research and evaluation seek evidence for developing practice (Fain, 2005). However, in reality this is challenging as there can often be a dichotomy between the two. Increasingly, medical educators and researchers are working as part of multidisciplinary teams so that a collective picture can be generated using 'evaluative research'. Not only is this a more efficient way of analysing information, but it also encourages the sharing of knowledge across professional borders (Mitchell et al, 2015).

It is evident that research and evaluation are of the utmost importance and will continue to be a cornerstone of both modern day evidence based medicine and medical education.

\section{References}

Albert M, Hodges B, Regehr G. (2007). Research in medical education: balancing sevice and science. Adv Heal Sci Edu Theory Pract. 2007; 12: 103-115. http://dx.doi.org/10.1007/s10459-006-9026-2

Albert M. (2004). Understanding the debate on medical education research: a sociological perspective. Acad Med. 2004: 79; 948-954. http://dx.doi.org/10.1097/00001888-200410000-00009

Cook DA. (2010). Twelve tips for evaluating educational programs. Medical teacher 2010; 32: 296-301. http://dx.doi.org/10.3109/01421590903480121

Deitrick JE \& Berson RC. (1953). Medical schools in the United States at mid-century. New York. NY: McGraw Hill; 1953.

Fain J. (2005). Is there a difference between evaluation and research? The diabetes educator 2005; 31: 154-155.

Ferris H \& Joyce P. (2015). International journal of higher education 2015 (4):2;38-43.

Flexner A. (1910). Medical education in the United States and Canada: Bulletin No. 4. New York, NY, The Carnegie Foundation for the advancement of teaching. 1910.

Frechtling J. (2007). Logic modelling methods in program evaluation. San Francisco: Joh Wiley \& Sons. 
Health Service Executive Policy. (2008). A user's guide to managing change in the Health Service Executive, Dublin. Available http://hse.ie/eng/staff/Resources/hrstrategiesreports/Improving_our_Services,_A_Guide_to_Managing_Change in_the_the_HSE_-_Oct_2008.pdf

Hedge MV et al. (2011). The use of small group teaching in under performers of class tests in biochemistry. JCDR 2011: 5(7):1428-9.

Hitchcock MA. (2002). Introducing professional educators into academic medicine: stories of exemplars. Adv Health Sci Edu Theory Pract 2002 (7):211-221.

Holzemer W. (1980) Research and evaluation: an overview. Quality review bulletin 1980; 3:31-34.

Hunt. (2011). National strategy for higher education to 2030 . Available at http://www.hea.ie/sites/default/files/national_strategy_for_higher_education_2030.pdf

Irish Medical Council- Monitoring and Audit. (2015) Available at http://www.medicalcouncil.ie/Information-for-Doctors/Professional-Competence/Monitoring-and-Audit/Audit-I nformation-for-Doctors.html

Joyce P. (2010). Evaluation research in education. Institute of leadership reports. Available at http://epubs.rcsi.ie/cgi/viewcontent.cgi?article=1006\&context=ilhmrep

Kuper A, Albert M, Hodges B et al. (2010). The origins of the field of medical education research. Acad Med 2010: 85; 1347-1353. http://dx.doi.org/10.1097/ACM.0b013e3181dce9a7

Larson MJ, Amodeo M, Storti SA et al. (2009). A novel CBT web course for the substance abuse workforce: community counselors' perceptions. Substance Abuse 2009; 30(1): 26-39. http://dx.doi.org/10.1080/08897070802611741

McNamara G, Joyce P \& O'Hara J. (2010). Evaluation of adult education and training programs. International encyclopaedia of education 2010 (3); 548-554. http://dx.doi.org/10.1016/b978-0-08-044894-7.01647-x

Michael Quinn Patton's Evaluation $5 \quad$ Cartoons. (2014) Available at http://freshspectrum.com/wp-content/uploads/2014/07/wpid-Photo-201407150621494.jpg

Mitchell R et al. (2015). Managing inclusiveness and diversity in teams: how leader inclusiveness affects performance through status and team identity. HR Management 2015:54;(2):217-239. http://dx.doi.org/10.1002/hrm.21658

Morrison J. Evaluation. (2003). BMJ 2003; 326: 385-387. http://dx.doi.org/10.1136/bmj.326.7385.385

Oxford Dictionary. (2015) Available at http://www.oxforddictionaries.com/definition/english/research

Patton M. 9. (2011). Developmental evaluation: applying complexity concepts to enhance innovation and use. New York: Guilford Press.

Philips JJ. (2003). Return on investment in training and performance improvement programs. $2^{\text {nd }}$ edition. Butterworth-Heinemann, Burlington MA.

Polit D \& Beck C. (2007). Nursing research: generating and assessing evidence for nursing practice. New York: Lippincott Williams \& Wilkins; 2007.

Royal College of Physicians- Medical education research. (2015) Available at https://www.rcpi.ie/article.php?locID=1.10.270.275

Salas E. (2009) Patient safety training evaluations; reflections on level 4 and more. Available at http://archive.ahrq.gov/news/events/conference/2009/salas/index.html

Strauss W \& Howe N. (2000). Millennials Rising: The Next Great Generation. New York, NY: Vintage Original. p. 370. ISBN 0-375-70719-0.

Stufflebeam DL (1983). The CIPP model for program evaluation. Evaluation in Education and Human Services Volume 6, 1983, pp 117-141.

Sufflebeam D \& Shinkfield A. (2007). Evaluation theory, models and applications. San Francisco, Jossey Bass/ John Wiley \& Sons Inc.

Tavakol M \& Sandars J. (2014). Quantitative and qualitative methods in medical education research: AMEE guide No. 90, Part 1. Medical Teacher 2014;36: 746-756. http://dx.doi.org/10.3109/0142159X.2014.915298 
Tavakol M, Gruppen L, Torabi S et al. (2010) Using evaluation research to improve medical education. The clinical teacher 2010; 7; 192-196. http://dx.doi.org/10.1111/j.1743-498x.2010.00383.x

Tavakol M, Murphy R, Rahemei-Madeseh M et al. (2008). The involvement of clinicians in medical education research. Qual Prim Care 16;335-40.

Taylor E \& Sheehan T. (2011). Perspectives on future of learning. Ashridge Business School. Accessed 05/09/11 from

www.ashridge.org.uk/Media-Library/Ashridge/PDFs/Publications/PerspectivesOnTheFutureOfLearning.pdf

Tyler RW. (1930). Measuring the ability to infer. Educational research bulletin 9(17): 475-480.

Webster CM \& Kenny J. (2011). Embedding research activities to enhance student learning. International journal of education management 2011;25(4): 361-377.

Weiss, C.H. (1972). Evaluation Research. Methods for Assessing Program Effectiveness. Prentice-Hall, Inc., Englewood Cliffs, New Jersey.

Yardley S \& Dornan T. (2012). Kirkpatrick's levels and education evidence. Med Education 2012; 46(1): 97-106. http://dx.doi.org/10.1111/j.1365-2923.2011.04076.x 